\title{
BRCA-Related Cancer Genetic Counseling is Indicated in Many Women Seeking Primary Care
}

\section{Daniel J. Parente, MD, PhD}

Background: Guidelines updated by the United States Preventive Services Task Force (USPSTF) in 2019 recommend referral to genetic counseling for asymptomatic women that have a family history of cancers potentially associated with variants in the breast cancer type 1 and 2 susceptibility genes (BRCA1 and BRCA2).

Methods: I performed a needs assessment for BRCA-related cancer genetic counseling among undifferentiated women seeking primary care at an urban, academic medical center with an underserved population. Adult, English-speaking women with outpatient primary care appointments were surveyed. Questions included personal and family history of potentially $B R C A$-related malignancies, history of genetic counseling and/or testing, and a version of the USPSTF-recommended 7-Question Family History Screening (FHS-7) tool, modified to promote accessibility among women with low health literacy.

Results: Out of 397 women, 97 women $(24.4 \% \pm 4.2 \%, 95 \%$ CI $)$ met criteria for referral to genetic counseling. Among women with referral indications, 80 women $(82.4 \% \pm 7.6 \%)$ had no prior contact with genetic counseling and/or testing services (comprising $20.1 \% \pm 3.9 \%$ of all women surveyed). The most common indication for $B R C A$-related genetic counseling referral was family history of female breast cancer before age 50 years.

Conclusions: The rate that undifferentiated women seeking primary care met 2019 USPSTF criteria for $B R C A$-related cancer genetic counseling referral $(24.4 \% \pm 4.2 \%)$ exceeds earlier estimates ( 4 to $5 \%$ ) but agrees with later, population-level estimates (24.1\%). Health systems will need to appropriately allocate capacity to genetic counseling services and/or reconsider the appropriateness of FHS-7 as a primary care risk-stratification tool. (J Am Board Fam Med 2020;33:885-893.)

Keywords: Breast Cancer, BRCA1 Gene, BRCA2 Gene, Early Detection of Cancer, Genetic Counseling, Genetic Predisposition, Health Literacy, Outpatients, Vulnerable Populations

\section{Introduction}

Guidelines updated by the United States Preventive Services Task Force (USPSTF) in 2019 recommend genetic counseling referral for asymptomatic women that have a family history of cancers potentially associated with variants in the breast cancer type 1 and 2 susceptibility genes (BRCA1 and BRCA2). ${ }^{1}$ BRCA1 and BRCA2 have been implicated in DNA repair and maintenance of genomic integrity. ${ }^{2}$ Variants

This article was externally peer reviewed.

Submitted 20 December 2019; revised 21 April 2020; accepted 26 April 2020.

From the Department of Family Medicine and Community Health, University of Kansas Medical Center, Kansas City, KS.

Funding: None.

Conflict of interest: None.

Corresponding author: Daniel J. Parente, MD, PhD, 3901 Rainbow Blvd, MS 4010, Kansas City, KS 66160 (E-mail: dparente@kumc.edu). in BRCA1 and BRCA2 have been linked to hereditary susceptibility to breast, ovarian, fallopian tube and peritoneal cancer in an autosomal dominant pattern. ${ }^{1,3-5}$ (For simplicity, I refer to breast, ovarian, fallopian tube, or peritoneal cancers as a group as "potentially $B R C A$ related cancers.") Moreover, increasing the proportion of women with a family history of the breast and/or ovarian cancer who receive genetic counseling has been identified as a public health objective in Healthy People $2020 .^{6}$

The implementation of $B R C A 1$ and $B R C A 2$ testing among women with a personal history of cancer, or who have already been referred to genetic counseling, has been well studied. ${ }^{7,8}$ However, there have been relatively few studies of the rate at which asymptomatic, undifferentiated women seeking primary care with a negative personal history of potentially $B R C A$-related cancers meet criteria for 
referral to genetic counseling. Prior analyses in 2013 and 2014 applying the 2005 USPSTF guidelines-which are more stringent than current guidelines-found indications for $B R C A$-related genetic counseling and testing in about $4 \%$ to $5 \%$ of women. ${ }^{9,10}$ However, a 2018 population-level analysis applying the National Health Interview Survey data and a variant of the USPSTF-approved 7-Question Family History Screening (FHS-7) tool, suggested that the rate of need-for-referral may be substantially higher (24.1\%). ${ }^{11}$

Thus, health systems may require substantial genetic counseling capacity to meet need for $B R C A$ related cancer genetic counseling and testing. However, the most relevant study population for health system capacity planning is not the population at large, but rather women actually empaneled with a primary care physician. Moreover, women presenting for primary care in underserved areas may sociodemographically differ from the general population. Indeed, the prevalence of pathologic BRCA1 and BRCA2 variants is influenced by population demographics. ${ }^{12}$ Here, I conducted a need assessment for $B R C A$-related referral to genetic counseling among undifferentiated women presenting to a primary care clinic at a midwestern, urban, academic medical center. These women have sociodemographic differences relative to the United States population at large, viz.: they are more likely to be Black/African American, and less likely to be White, Hispanic, or married.

\section{Methods}

\section{Survey Design}

I distributed a 12-item paper survey to adult, English-speaking women who presented for outpatient appointments in a primary care clinic affiliated with an academic medical center in an underserved, midwestern, urban community. The following questions were included on the survey (exact formatting shown in Supplemental Materials):

1. Has anyone in your family had cancer of the breast, ovary, fallopian tube or peritoneum (abdominal lining)?

2. Have you had cancer of the breast, ovary, fallopian tube or peritoneum (abdominal lining)?

3. Have you ever had a genetic test to determine your risk of breast cancer?

4. Have you ever discussed your breast cancer risk with a genetic counselor?
5. Has anyone in your family had a genetic test for breast cancer risk?

6. Did any parent, child or sibling have breast cancer?

7. Did any parent, child or sibling have ovarian cancer?

8. Did any man in your family have breast cancer?

9. Did any woman in your family have both breast and ovarian cancer?

10. Did any woman in your family have breast cancer before age 50 ?

11. Did 2 or more relatives have breast and/or ovarian cancer?

12. Did 2 or more relatives have breast and/or bowel cancer?

Current guidelines ${ }^{1}$ recommend screening women with a family history of potentially $B R C A$-related malignancy (breast, ovarian, fallopian tube, or peritoneum) for referral to genetic counseling. However, guidelines indicate that screening women without a family history of potentially BRCA-related malignancy is contraindicated. Therefore, to avoid harm and reduce screening burden, I instructed women with a negative family history of potentially $B R C A$-related cancers (question 1) to discontinue the survey after the first question, and women with either a prior history of breast cancer (question 2) or BRCA-related genetic testing (question 3) to discontinue the survey after question 3. Question 4 elicits prior history of genetic counseling contact. Questions 6 to 12 implement a modified version in the FHS-7 tool, ${ }^{13}$ one of the validated screening instruments recommended by the USPSTF. The USPSTF recommends that any positive response to the FHS-7 should initiate referral. To make questions more accessible to women with low health literacy, the questions were edited for verbal and conceptual simplicity, replacing "first-degree relatives" with "parent, child, or sibling" and eliminating reference to "bilateral" breast cancer. The former change uses simpler language without impacting the estimate of the underlying need-forreferral rate. The latter change will induce an underestimate of the underlying rate of need for genetic counseling, but this was considered an acceptable tradeoff to achieve conceptual simplicity.

\section{Survey Implementation}

Paper surveys were distributed to adult ( $\geq 18$ years old), English-speaking women in August 2019 by the clinic front desk and collected by a 
medical assistant or nurse when the patient was called to an examination room. Surveys were completed without additional assistance. Patients of 47 distinct providers were included in the analysis. Providers comprised 20 attending physicians (165 patients), 23 resident physicians (190 patients), 3 midlevel providers (41 patients) and 1 pharmacist (1 patient). A total of 455 surveys were distributed and 404 were returned (88.7\% response rate). Five women were surveyed twice. For 3 of these women, only the more complete version of their survey was retained. Two double-surveyed women provided inconsistent answers and both responses were excluded, resulting in 397 nonduplicate responses.

\section{Data Analysis}

Data were analyzed using custom software written in Python (version 3.7) and in $\mathrm{R}$ (version 3.6.1). Nonresponses were treated as missing data, without imputation. All survey questions included a "Do not know" answer, which was treated as equivalent to "No" for most analyses. The rationale for treating "Do not know" answers in this manner is that this is most compatible with how screening would actually be used in clinical situations. For example, a woman with an unknown family history of potentially $B R C A$-related malignancy would not be screened. Similarly, a "Do not know" response to questions 6 to 12 would not otherwise be a clinical indication for genetic counseling referral. For example, a woman would not be referred to genetic counseling just because they were not sure if a woman in their family had breast cancer before age 50. Prior history of genetic counseling and/or testing was inferred from a positive response to either questions 3 or 4 . An indication for referral to genetic counseling and/or testing was inferred to exist if 1 ) there was a personal history of genetic counseling and/or testing, or 2) any 1 of questions 6 to 12 were answered "Yes" (consistent with USPSTF recommendations). Two-tailed proportional $t$-test were used to compare proportions. Proportions are reported as point estimates $\pm 95 \%$ $\mathrm{CI}$, where the $95 \% \mathrm{CI}$ half-width was calculated using $1.96^{*} \sigma_{\mathrm{p}}$ with $\sigma_{\mathrm{p}}{ }^{2}=\mathrm{p}(1-\mathrm{p}) / \mathrm{n}$ for sample size $\mathrm{n}$ and proportion $\mathrm{p}$. For all estimates thus computed, I verified $p^{*} n>5$ and $(1-p)^{*} n>5$.

\section{Human Subjects Review}

The study was approved by the University of Kansas Medical Center Institutional Review Board as part of a quality improvement initiative.

\section{Results}

\section{Sample Demographics}

The demographic profile of nonduplicate survey respondents is summarized in Table 1. Ages ranged between 18 and 91 years, with median age of 46 years. Relative to the United States population, ${ }^{14,15}$ Black/African American women are over-represented $(P<.001)$, while White and Hispanic women are under-represented (both $P<.001$ ). Participants were also less likely to be married $(P<.001)$. Most women had private insurance $(61.7 \%)$, with the remainder covered by Medicare (26.7\%) or Medicaid (11.6\%).

\section{Table 1. Demographics}

\begin{tabular}{|c|c|c|}
\hline Demographic & Count & Percent \\
\hline \multicolumn{3}{|l|}{ Age (Years) } \\
\hline 18 to 19 & 9 & 2.2 \\
\hline 20 to 29 & 62 & 15.6 \\
\hline 30 to 39 & 83 & 20.9 \\
\hline 40 to 49 & 65 & 16.3 \\
\hline 50 to 59 & 76 & 19.1 \\
\hline 60 to 69 & 64 & 16.1 \\
\hline 70 to 79 & 29 & 7.3 \\
\hline$>79$ & 9 & 2.2 \\
\hline \multicolumn{3}{|l|}{ Marital Status } \\
\hline Single & 179 & 45.0 \\
\hline Married & 137 & 34.5 \\
\hline Separated & 5 & 1.2 \\
\hline Divorced & 49 & 12.3 \\
\hline Widowed & 26 & 6.5 \\
\hline Other & 1 & 0.2 \\
\hline \multicolumn{3}{|l|}{ Race } \\
\hline American Indian or Alaska Native & 2 & 0.5 \\
\hline Asian & 10 & 2.5 \\
\hline Black or African American & 155 & 39.0 \\
\hline Native Hawaiian or Other Pacific Islander & 2 & 0.5 \\
\hline White & 183 & 46.0 \\
\hline Other & 37 & 9.3 \\
\hline Two or more races & 5 & 1.2 \\
\hline Declined & 3 & 0.7 \\
\hline \multicolumn{3}{|l|}{ Ethnicity } \\
\hline Hispanic, Latino, or Spanish origin & 40 & 10.0 \\
\hline Not Hispanic, Latino, or Spanish origin & 353 & 88.9 \\
\hline Declined & 4 & 1.0 \\
\hline \multicolumn{3}{|l|}{ Insurance status } \\
\hline Private & 245 & 61.7 \\
\hline Medicaid & 46 & 11.6 \\
\hline Medicare & 106 & 26.7 \\
\hline
\end{tabular}

Demographic Profile of All 397 Non-Duplicate Survey Respondents. 


\section{Need for BRCA-Related Cancer Genetic Counseling}

Determining the total and unmet need for BRCArelated referral to genetic counseling requires integration of information about 1) family history of potentially $B R C A$-related cancers, 2) personal history of potentially $B R C A$-related cancers, 3 ) genetic testing and/or counseling status, and 4) risk stratification score using the modified FHS-7 instrument. I considered any woman to have "need" if they met USPSTF referral criteria, and for that need to have been met if they had prior $B R C A$-related genetic testing and/or counseling. The flow of women sequentially satisfying (or not) these criteria is shown in Figure 1 and response counts for each question are shown in Table 2.

I first determined how many women have a positive family history of potentially $B R C A$-related malignancies. Positive family history was present in 168 women $(42.3 \% \pm 4.9 \%)$, and absent in 216 women $(54.4 \% \pm 4.9 \%)$. Thirteen women did not provide information about their family history of potentially $B R C A$-related malignancies.

Next, I analyzed the 168 women with a positive family history of potentially $B R C A$-related cancer to determine whether they had 1 ) a personal history of potentially $B R C A$-related cancer (and therefore require individualized care), or 2) prior experience with genetic counseling and/or testing (indicating prior need that has already been met). Fifteen women did not provide enough information to determine whether they had a personal history of cancer and/or prior experience with genetic counseling and/or testing and were excluded from further analysis. Eight women $(5.2 \% \pm 3.5 \%$ of women with positive family history) had a personal history of potentially $B R C A$-related malignancy while 145 women $(94.7 \% \pm 3.5 \%)$ had a negative personal history of cancer. Seventeen women $(11.1 \% \pm 5.0 \%$ with positive family history) had prior contact with genetic counseling and/or genetic testing (Supplemental Table 1). Therefore, both personal history of potentially $B R C A$ related cancer and contact with genetic counseling and/ or testing were very uncommon.

I then assessed for indications for referral for $B R C A$ related genetic counseling among the remaining 128 women with potentially unmet genetic counseling need (ie, positive family history, negative personal history, and no prior contact with genetic counseling and/or testing). Eighty women $(62.5 \% \pm 8.4 \%$ of women with potential need and $20.1 \% \pm 3.9 \%$ of all nonduplicate survey respondents) had an unmet indication for genetic counseling and/or testing referral. Genetic counseling referral was not indicated for 33 women (25.8\% $\pm 7.6 \%$ of women with potential need and $8.3 \% \pm 2.7 \%$ of all respondents). In a further 15 women, need for genetic counseling and/or testing could not be inferred from the responses provided. (Some women left a subset of questions 6 to 12 unanswered. Presence of need for genetic counseling referral can be inferred when any of questions 6 to 12 are answered positively, but absence of need requires all questions 6 to 12 to be answered negatively.)

I further investigated whether total need for genetic counseling among all women, total need for genetic counseling among women with positive family history, or unmet need among women with

Figure 1. Analytic flow of survey responses. Numbers refer to the total number of surveys/patients involved in each step. Detailed explanation of these analyses are given in the Results section. Abbreviations: Fam Hx, family history; PHx, personal history; GC, genetic counseling.

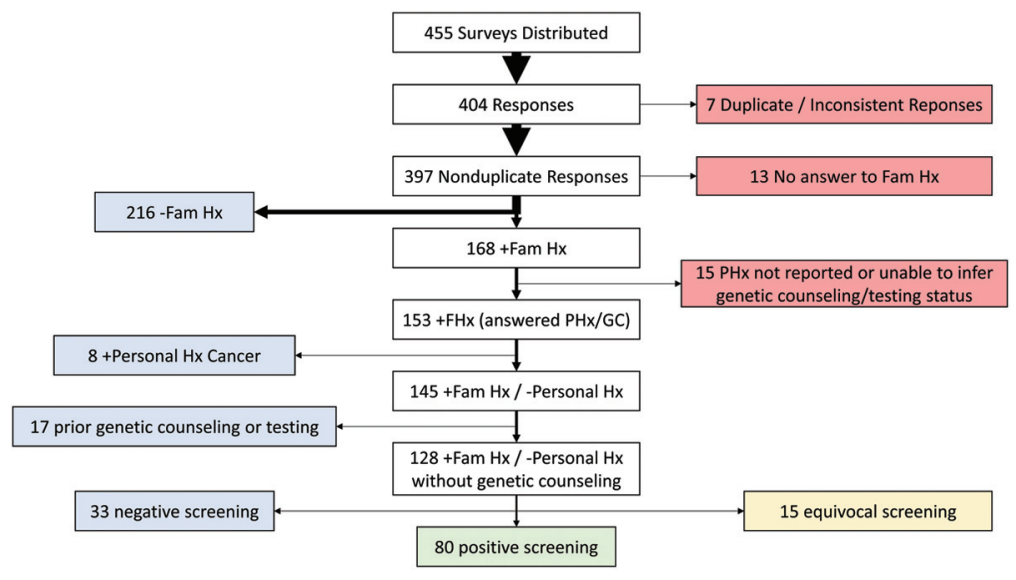


Table 2. Frequency of Responses by Patient Category Including All 397 Non-Duplicate Respondents ("All"), Patients with a Positive Family History $(+\mathrm{FHx})$ of Potentially BRCA-Related Malignancies and Patients with Positive Family History Who Also Have a Negative Personal History of Potentially BRCA-Related Malignancies $(+$ FHx - PHx $)$

\begin{tabular}{|c|c|c|c|c|c|c|}
\hline \multirow[b]{2}{*}{ Question } & \multicolumn{2}{|c|}{ All } & \multicolumn{2}{|c|}{$+\mathrm{FHx}$} & \multicolumn{2}{|c|}{$+\mathrm{FHx}-\mathrm{PHx}$} \\
\hline & $\mathrm{N}$ & $\%$ & $\mathrm{~N}$ & $\%$ & $\mathrm{~N}$ & $\%$ \\
\hline Total & 397 & 100 & 168 & 100 & 145 & 100 \\
\hline \multicolumn{7}{|c|}{$\begin{array}{l}\text { 1. Has anyone in your family had cancer of the } \\
\text { breast, ovary, fallopian tube or peritoneum } \\
\text { (abdominal lining)? }\end{array}$} \\
\hline Yes & 168 & 42 & 168 & 100 & 145 & 100 \\
\hline No & 180 & 45 & 0 & 0 & 0 & 0 \\
\hline Don't know & 36 & 9 & 0 & 0 & 0 & 0 \\
\hline No answer & 13 & 3 & 0 & 0 & 0 & 0 \\
\hline \multicolumn{7}{|l|}{$\begin{array}{l}\text { 2. Have you had cancer of the breast, ovary, } \\
\text { fallopian tube or peritoneum } \\
\text { (abdominal lining)? }\end{array}$} \\
\hline Yes & 10 & 3 & 9 & 5 & 0 & 0 \\
\hline No & 239 & 60 & 139 & 83 & 136 & 94 \\
\hline Don't know & 12 & 3 & 9 & 5 & 9 & 6 \\
\hline No answer & 136 & 34 & 11 & 7 & 0 & 0 \\
\hline \multicolumn{7}{|c|}{$\begin{array}{l}\text { 3. Have you ever had a genetic test to determine } \\
\text { your risk of breast cancer? }\end{array}$} \\
\hline Yes, my risk was normal & 18 & 5 & 13 & 8 & 11 & 8 \\
\hline Yes, my risk was increased & 2 & 1 & 2 & 1 & 1 & 1 \\
\hline Yes, but I do not know the result & 5 & 1 & 4 & 2 & 3 & 2 \\
\hline No, I have not & 207 & 52 & 124 & 74 & 118 & 81 \\
\hline I don't know if I have been tested & 16 & 4 & 9 & 5 & 9 & 6 \\
\hline No answer & 149 & 38 & 16 & 10 & 3 & 2 \\
\hline \multicolumn{7}{|c|}{$\begin{array}{l}\text { 4. Have you ever discussed your breast cancer risk } \\
\text { with a genetic counselor? }\end{array}$} \\
\hline Yes & 10 & 3 & 9 & 5 & 7 & 5 \\
\hline No & 208 & 52 & 125 & 74 & 115 & 79 \\
\hline Don't know & 7 & 2 & 5 & 3 & 4 & 3 \\
\hline No answer & 172 & 43 & 29 & 17 & 19 & 13 \\
\hline \multicolumn{7}{|c|}{$\begin{array}{l}\text { 5. Has anyone in your family had a genetic test } \\
\text { for breast cancer risk? }\end{array}$} \\
\hline Yes, but risk was normal & 18 & 5 & 12 & 7 & 11 & 8 \\
\hline Yes, and risk was increased & 7 & 2 & 6 & 4 & 5 & 3 \\
\hline Yes, but I do not know the result & 11 & 3 & 9 & 5 & 7 & 5 \\
\hline No, they have not & 96 & 24 & 52 & 31 & 47 & 32 \\
\hline I don't know if anyone has been tested & 94 & 24 & 59 & 35 & 54 & 37 \\
\hline No answer & 171 & 43 & 30 & 18 & 21 & 14 \\
\hline \multicolumn{7}{|l|}{$\begin{array}{l}\text { 6. Did any parent, child or sibling have breast } \\
\text { cancer? }\end{array}$} \\
\hline Yes & 38 & 10 & 38 & 23 & 33 & 23 \\
\hline No & 189 & 48 & 99 & 59 & 90 & 62 \\
\hline Don't know & 19 & 5 & 7 & 4 & 6 & 4 \\
\hline No answer & 151 & 38 & 24 & 14 & 16 & 11 \\
\hline \multicolumn{7}{|c|}{$\begin{array}{l}\text { 7. Did any parent, child or sibling have ovarian } \\
\text { cancer? }\end{array}$} \\
\hline Yes & 23 & 6 & 23 & 14 & 16 & 11 \\
\hline No & 197 & 50 & 110 & 65 & 103 & 71 \\
\hline
\end{tabular}




\begin{tabular}{|c|c|c|c|c|c|c|}
\hline \multirow[b]{2}{*}{ Question } & \multicolumn{2}{|c|}{ All } & \multicolumn{2}{|c|}{$+\mathrm{FHx}$} & \multicolumn{2}{|c|}{$+\mathrm{FHx}-\mathrm{PHx}$} \\
\hline & $\mathrm{N}$ & $\%$ & $\mathrm{~N}$ & $\%$ & $\mathrm{~N}$ & $\%$ \\
\hline Don't know & 27 & 7 & 13 & 8 & 11 & 8 \\
\hline No answer & 150 & 38 & 22 & 13 & 15 & 10 \\
\hline \multicolumn{7}{|c|}{ 8. Did any man in your family have breast cancer? } \\
\hline Yes & 2 & 1 & 2 & 1 & 1 & 1 \\
\hline No & 217 & 55 & 131 & 78 & 119 & 82 \\
\hline Don't know & 28 & 7 & 12 & 7 & 10 & 7 \\
\hline No answer & 150 & 38 & 23 & 14 & 15 & 10 \\
\hline \multicolumn{7}{|c|}{$\begin{array}{l}\text { 9. Did any woman in your family have both breast } \\
\text { and ovarian cancer? }\end{array}$} \\
\hline Yes & 28 & 7 & 27 & 16 & 22 & 15 \\
\hline No & 176 & 44 & 94 & 56 & 87 & 60 \\
\hline Don't know & 40 & 10 & 23 & 14 & 19 & 13 \\
\hline No answer & 153 & 39 & 24 & 14 & 17 & 12 \\
\hline \multicolumn{7}{|c|}{$\begin{array}{l}\text { 10. Did any woman in your family have breast } \\
\text { cancer before age 50? }\end{array}$} \\
\hline Yes & 59 & 15 & 58 & 35 & 56 & 39 \\
\hline No & 149 & 38 & 67 & 40 & 59 & 41 \\
\hline Don't know & 36 & 9 & 18 & 11 & 14 & 10 \\
\hline No answer & 153 & 39 & 25 & 15 & 16 & 11 \\
\hline \multicolumn{7}{|c|}{$\begin{array}{l}\text { 11. Did } 2 \text { or more relatives have breast and/or } \\
\text { ovarian cancer? }\end{array}$} \\
\hline Yes & 55 & 14 & 54 & 32 & 47 & 32 \\
\hline No & 149 & 38 & 69 & 41 & 65 & 45 \\
\hline Don't know & 41 & 10 & 21 & 13 & 16 & 11 \\
\hline No answer & 152 & 38 & 24 & 14 & 17 & 12 \\
\hline \multicolumn{7}{|c|}{$\begin{array}{l}\text { 12. Did } 2 \text { or more relatives have breast and/or } \\
\text { bowel cancer? }\end{array}$} \\
\hline Yes & 30 & 8 & 30 & 18 & 25 & 17 \\
\hline No & 156 & 39 & 78 & 46 & 73 & 50 \\
\hline Don't know & 53 & 13 & 32 & 19 & 28 & 19 \\
\hline No answer & 158 & 40 & 28 & 17 & 19 & 13 \\
\hline
\end{tabular}

need for genetic counseling was associated with demographic parameters (age, race, ethnicity, marital status and insured status). No statistically significant association, however, was found (Supplemental Table 2).

In addition, I determined the frequency with which each FHS-7 survey response produced a medical indication for referral to genetic counseling in women with unmet need for genetic counseling. The most common indications for referral were female breast cancer before age 50 years (question 10; 47 women), multiple relatives with breast and/ or ovarian cancer (question 11; 36 women), firstdegree relative with breast cancer (question 6; 26 women), multiple relatives with breast and/or bowel cancer (question 12; 19 women), female relative with both breast and ovarian cancer (question
9; 18 women), and first-degree relative with ovarian cancer (question 7; 12 women). Interestingly, no woman with unmet need for genetic counseling reported history of breast cancer in a male relative (question 8; although 1 woman with previously met need for genetic counseling did report this). The total sum of referral indications does not equal 80 women because some women had multiple indications for referral.

\section{Discussion}

Of a total of 397 adult, English-speaking women, 97 women $(24.4 \% \pm 4.2 \%)$ had need for genetic counseling and/or testing services according to the FHS-7 screening tool. This need was mostly unmet 
(80 women; $82.4 \% \pm 7.6 \%$ of total need). Prior evidence of genetic counseling and/or testing was found in only 17 women $(11.7 \% \pm 5.2 \%$ of women with positive family history, but negative personal history, of potentially $B R C A$-related cancer). An additional 8 women had a personal history of a potentially $B R C A$-related cancer, requiring individualized care. I did not further explore indications for screening in these women, as a large body of literature already exists on genetic testing for $B R C A$ variants in women with a current or historic malignancy. ${ }^{7,8}$

This result is at variance with earlier estimates of the rate at which women seeking primary care meet USPSTF criteria for genetic counseling referral but is concordant with a more recent population-level analysis. A 2014 analysis of 486 Women's Health Clinic patients at the Virginia Commonwealth University Health System suggested that about 1 in 22 women seeking primary care $(4.5 \%)$ met referral criteria. ${ }^{10}$ Similarly, a larger analysis in 2013 of 2524 women associated with the Henry Ford Health System in Detroit, Michigan, suggested about $5 \%$ of women met referral criteria. ${ }^{9}$ Here, I find that about 1 in $4(24.4 \% \pm 4.2 \%)$ women seeking primary care have need of $B R C A$-related cancer genetic counseling and/or testing, which markedly differs from the prior estimates $(P<.001$ for each comparison).

The likely source of this variance is the use of different referral criteria. This analysis applies the current 2019 USPSTF guidelines. Both prior analyses applied the USPSTF referral recommendations from 2005. ${ }^{16}$ At that time, there were no standardized referral criteria available. The 2005 high-risk criteria that were therefore suggested by the USPSTF were more stringent than the modified FHS-7 criteria applied here. For example, the 2005 criteria require not merely family history of breast cancer in a first degree relative, but rather 2 first-degree relatives with breast cancer, at least 1 of which occurred under age 50 years.

This explanation as the source of the disagreement in genetic counseling and/or testing indication rates is supported by agreement with recent population-level evidence that suggests $24 \%$ of adult women in the population may meet genetic counseling and/or testing referral criteria using modern screening methods (ie, FHS-7). ${ }^{11}$ This referral indication rate is indistinguishable from the rate I observed $(P=.92)$, despite significant sociodemographic differences between women in the underserved population studied here and the United States general population.

There are several caveats that should be considered when interpreting these results. First, the study was conducted at a single center with some sociodemographic differences from the population at large. Second, the survey was limited to Englishspeaking women; the experience of non-English speakers is not captured by this analysis. Third, all women in this study were insured either privately $(61.7 \%)$ or publicly $(38.2 \%)$. Analyses of uninsured women are highly relevant for improving population health and should be undertaken in subsequent studies. Fourth, the survey was conducted in a primary care clinic of an academic medical center; caution should be exercised when generalizing these results to a community, office-based setting. Fifth, I did not collect information about educational attainment or household income. Sixth, surveys were completed by women without additional assistance from nursing or research staff. Although steps were taken to make the survey broadly accessible to even women with low health literacy, it is possible that some questions might have been answered incorrectly due to limited understanding of the questions themselves or due to limited knowledge of their own medical history. In addition, complex family structures might result in confusion about how to answer certain questions about family history.

The need-for-referral rate reported here is likely an underestimate, driven by 2 factors. First, I used a version of the validated and USPSTF-recommended FHS-7 screening instrument that had been modified for verbal and conceptual simplicity so that screening would be more accessible to women with low health literacy (see Methods). This variation neglects family history of bilateral breast cancer as a referral indication. Second, while this project was underway the USPSTF updated $B R C A$ related genetic counseling referral recommendations to include consideration of 1) ancestry associated with BRCA mutations (eg, Ashkenazi Jewish ancestry), and 2) prior diagnosis of potentially $B R C A$-related cancers that have been treated and are now considered cancer free. ${ }^{1}$ I did not here investigate ancestry-related indications for referral to genetic counseling. Similarly, I did not investigate indications for $B R C A$-related genetic counseling and/or testing in women with a prior history of potentially $B R C A$-related malignancy, as this has already been extensively studied in the specialized 
genetic counseling and oncologic literature. ${ }^{7,8}$ The impact of these changes on the need-for-referral rate is nevertheless likely to be small in view of the low population prevalence of individuals with $B R C A$ linked ancestry and the infrequency of reported personal history of potentially $B R C A$-related cancer (8 women, $2.0 \% \pm 1.4 \%$ of the total sample surveyed). Moreover, underestimation of the true rate-of-referral does not change the underlying conclusion that many (approximately 1 in 4) women have need for $B R C A$-related genetic counseling referral when applying the FHS-7 screening tool.

If USPSTF recommendations are to be implemented, a sizable fraction of women who are empaneled with a primary care practice may thus require referral to genetic counseling and/or testing services. Health systems will need to appropriately allocate capacity to genetic counseling services and/or develop alternative methods to risk-stratify women directly from primary care. Indeed, the rate at which women have indications for BRCA-related cancer genetic counseling and/or testing may differ if an alternative USPSTF-recommended screening instruments were used, viz.: the Ontario Family History Assessment Tool, the Manchester Scoring System, the Referral Screening Tool, the Pedigree Assessment tool or the International Breast Cancer Intervention Study instrument or brief BRCAPRO., ${ }^{1,9,17-19}$ Moreover, the prevalence of pathogenic BRCA variants in the population likely does not exceed $0.31 \%$. $^{3}$ The vast majority women referred from primary care using current recommendations are thus likely to not have pathogenic $B R C A$ variants.

Provision of genetic counseling services for $B R C A$ related cancer risk to $24.4 \%$ of women would have significant costs. A detailed analysis of the economic impacts is beyond the scope of this work, but the approximate magnitude of their impact can be estimated. Consider the yearly cost of keeping up with new demand by considering the cost required to refer indicated women who attain the median age of the studied population (46 years). US census data from 2018 estimates there are 10,483,140 women aged 45 to 49 years. $^{20}$ Assuming even distribution, there would be approximately $2,134,406$ women aged 46 years. If $24.4 \%$ (the estimate from this study) of these women require BRCA-related genetic counseling, this requires 511,577 yearly genetic counseling appointments. The Bureau of Labor Statistics estimates that the median genetic counselor earns $\$ 80,370$ per year. ${ }^{21}$ If a genetic counselor works 40 hours per week, 50 weeks per year, and each appointment last 60 minutes, this would require 256 genetic counsellors at an estimated yearly cost of $\$ 20,574,720$. These costs would be incurred solely in providing $B R C A$-related genetic counseling services to meet new yearly demand, completely neglecting the backlogged demand for women at all other ages in whom genetic counseling is indicated.

Comparison of the rate at which various screening instruments indicate genetic counseling referral should be the subject of further studies. Some instruments - such as the FHS-7 used in this study -have quite broad referral indications. For example, the FHS-7 tool does not distinguish between a family history of breast cancer in a first-degree relative who was 30 years old at time of onset, from a family member who was 80 years old. Both women would be referred equally, despite the enrichment of $B R C A 1 / 2$ mutations in women with young-onset breast cancer. ${ }^{22}$ Other screening tools, such as the Manchester Scoring System, Referral Screening Tool, and the Pedigree Assessment Tool distinguish early-onset from late-onset breast cancer in first-degree relatives. The breadth of referral indications and cost efficacy implied by each risk assessment tool should be carefully considered in future preventive care guidelines. Moreover, ongoing development of high-sensitivity/high specificity predictive classifiers, appropriate for use in the primary care setting, should also continue.

We thank Megan Murray, MHSA, clinical data manager for Family Medicine and Community Health at the University of Kansas Medical Center, for assistance in obtaining demographic data for patients from the electronic medical record. We thank the University of Kansas Medical Center Family Medicine clinic nursing and support staff for assistance in distributing and collecting the surveys.

To see this article online, please go to: http://jabfm.org/content/ 33/6/885. full.

\section{References}

1. United States Preventative Services Task Force. Risk Assessment, genetic counseling, and genetic testing for BRCA-related cancer: US Preventive Services Task Force recommendation statement. JAMA 2019;322:652-65.

2. Gorodetska I, Kozeretska I, Dubrovska A. BRCA genes: the role in genome stability, cancer stemness and therapy resistance. J Cancer 2019;10:2109-27.

3. Anglian Breast Cancer Study Group. Prevalence and penetrance of BRCA1 and BRCA2 mutations 
in a population-based series of breast cancer cases. Br J Cancer 2000;83:1301-8.

4. Miki Y, Swensen J, Shattuck-Eidens D, et al. A strong candidate for the breast and ovarian cancer susceptibility gene BRCA1. Science 1994;266:66-71.

5. Norquist BM, Garcia RL, Allison KH, et al. The molecular pathogenesis of hereditary ovarian carcinoma: alterations in the tubal epithelium of women with BRCA1 and BRCA2 mutations. Cancer 2010;116:5261-71.

6. Department of Health and Human Services Office of Disease Prevention and Health Promotion. Healthy People 2020: Genomics. 2019. Available from: https://www.healthypeople.gov/2020/topicsobjectives/topic/genomics/objectives. Accessed October 4, 2019.

7. Neff RT, Senter L, Salani R. BRCA mutation in ovarian cancer: testing, implications and treatment considerations. Ther Adv Med Oncol 2017;9:519-31.

8. Valencia OM, Samuel SE, Viscusi RK, et al. The role of genetic testing in patients with breast cancer: a review. JAMA Surg 2017;152:589-94.

9. Bellcross CA, Leadbetter S, Alford SH, et al. Prevalence and healthcare actions of women in a large health system with a family history meeting the 2005 USPSTF recommendation for BRCA genetic counseling referral. Cancer Epidemiol Biomarkers Prev 2013;22:728-35.

10. Quillin JM, Krist AH, Gyure M, et al. Patientreported hereditary breast and ovarian cancer in a primary care practice. J Commun Genet 2014;5:179-83.

11. Hull LE, Haas JS, Simon SR. Provider discussions of genetic tests with U.S. women at risk for a BRCA mutation. Am J Prev Med 2018;54:221-8.

12. Malone KE, Daling JR, Doody DR, et al. Prevalence and predictors of BRCA1 and BRCA2 mutations in a population-based study of breast cancer in white and black American women ages 35 to 64 years. Cancer Res 2006;66:8297-308.

13. Ashton-Prolla P, Giacomazzi J, Schmidt AV, et al. Development and validation of a simple questionnaire for the identification of hereditary breast cancer in primary care. BMC Cancer 2009;9:283.

14. U.S. Census Bureau. 2019. QuickFacts: United States. Available from: https://www.census.gov/quickfacts/ fact/table/US/PST045218. Accessed October 4, 2019.

15. U.S. Census Bureau. 2018. Historical marital status tables. Available from: https://www.census.gov/data/ tables/time-series/demo/families/marital.html. Accessed October 4, 2019.

16. US Preventive Services Task Force. Genetic risk assessment and BRCA mutation testing for breast and ovarian cancer susceptibility: recommendation statement. Ann Intern Med 2005;143:355-61.

17. Gilpin C, Carson N, Hunter A. A preliminary validation of a family history assessment form to select women at risk for breast or ovarian cancer for referral to a genetics center. Clin Genet 2000;58:299308.

18. Antoniou AC, Hardy R, Walker L, et al. Predicting the likelihood of carrying a BRCA1 or BRCA2 mutation: validation of BOADICEA, BRCAPRO, IBIS, Myriad and the Manchester scoring system using data from UK genetics clinics. J Med Genet 2008;45:425-31.

19. Teller P, Hoskins KF, Zwaagstra A, et al. Validation of the pedigree assessment tool (PAT) in families with BRCA1 and BRCA2 mutations. Ann Surg Oncol 2010;17:240-6.

20. U.S. Census Bureau. National Population by Characteristics: 2010-2019. Available from: https:// www.census.gov/data/tables/time-series/demo/popest/ 2010s-national-detail.html. Accessed March 25, 2020.

21. Bureau of Labor Statistics. Occupational Employment and Wages, May 2018: 29-9092 Genetic Counselors. Available from: https:/www.bls.gov/oes/2018/may/ oes299092.htm. Accessed March 25, 2020.

22. Peto J, Collins N, Barfoot R, et al. Prevalence of BRCA1 and BRCA2 gene mutations in patients with early-onset breast cancer. J Natl Cancer Inst 1999;91:943-9. 